\title{
Chapter 2 \\ Hypotheses for a Theory of Production in the Context of Industrie 4.0
}

\author{
Günther Schuh, Christina Reuter, Annika Hauptvogel \\ and Christian Dölle
}

\begin{abstract}
Significant increase in productivity of production systems has been an effect of all past industrial revolutions. In contrast to those industrial revolutions, which were driven by the production industry itself, Industrie 4.0 is pushed forward by an enormous change within the current society due to the invention and frequent usage of social networks in combination with smart devices. This new social behaviour and interaction now makes its presence felt in the industrial sector as companies use the interconnectivity in order to connect production systems and enhance collaboration. As employees bring their own smart devices to work the interconnectivity is brought into the companies as well and Industrie 4.0 is pushed into the companies rather than initiated by the companies themselves. On top of productivity improvement within production the fourth industrial revolution opens up new potentials in indirect departments such as engineering. This focus differentiates Industrie 4.0 from the first three industrial revolutions, which mainly focused on productivity increase by optimising the production process. Within the Cluster of Excellence "Integrative Production Technology for High-Wage Countries" of the RWTH Aachen University four mechanisms were developed which describe Industrie 4.0. The mechanisms "revolutionary product lifecycles", "virtual engineering of complete value chains", "better performing than engineered" and "revolutionary short value chains" can be achieved within an Industrie 4.0-environment. This environment is based on the four enablers "IT-Globalisation", "single source of truth", "automation" and "cooperation" and enhances collaboration productivity. Therefore the present paper examines and introduces hypotheses for a production theory in the context of Industrie 4.0. For each mechanism two hypotheses are presented which explain how the respective target state can be achieved. The transmission of these mechanisms into producing companies leads to an Industrie 4.0 capable environment strengthening competitiveness due to
\end{abstract}

\footnotetext{
G. Schuh · C. Reuter · A. Hauptvogel · C. Dölle $(\bowtie)$

Laboratory for Machine Tools and Production Engineering (WZL), RWTH Aachen

University, Steinbachstr. 19, 52074 Aachen, Germany

e-mail: c.doelle@wzl.rwth-aachen.de

(C) The Author(s) 2015

C. Brecher (ed.), Advances in Production Technology,

Lecture Notes in Production Engineering, DOI 10.1007/978-3-319-12304-2_2
} 
increased collaboration productivity within the direct and especially indirect departments. The specified hypotheses were developed within the framework of the Cluster of Excellence "Integrative Production Technology for High-Wage Countries" of the RWTH Aachen University.

\subsection{Introduction}

This paper continues the work described in "Collaboration Mechanisms to increase Productivity in the Context of Industrie 4.0" (Schuh et al. 2014a). Therefore the present paper proceeds by giving a short introduction regarding Industrie 4.0-enablers. Each mechanisms presented in Schuh et al. (2014a) is then briefly described before two hypotheses for each mechanism are introduced.

The effect of past industrial revolutions has always been a significant increase in productivity (Schuh et al. 2013a). The increase in productivity started with the first industrial revolution due to the introduction of the steam engine and continued with the Taylorism and the automation as well as computerising (Schuh et al. 2013a, 2014b). Thus automation and computerising already increased productivity within the indirect departments the first three industrial revolutions mainly took place on a shop-floor level. Industrie 4.0 continues to shift the productivity increase even more, as especially indirect departments such as engineering are enhanced due to the Industrie 4.0-enablers and further support of software (Russwurm 2013). Therefore this industrial revolution supports decision making, simulation and engineering performance by aid of collaboration. The mentioned performance increase is represented by four mechanisms of increased productivity, which are supported by the Industrie 4.0-enablers (Schuh et al. 2014a).

This paper reflects the mechanisms of productivity increase and introduces hypotheses on how these target states are to be achieved within an Industrie 4.0-environment.

\subsection{Collaboration Productivity Due to Industrie 4.0-Enablers}

Within the literature the industrial change due to the fourth industrial revolution addresses diverse aspects of Industrie 4.0 and therefore differs widely in its interpretation (Wahlster 2013; Brettel et al. 2014a; Imtiaz and Jasperneite 2013). Still most of the authors agree with the high potential of productivity increase which accompanies the current transformation process. As stated earlier Industrie 4.0 is not initiated on a shop-floor level and therefore companies have to take measures in their own hands to introduce Industrie 4.0-enablers into their companies to profit from the current change in society and technology (Kagermann et al. 2013). 
Fig. 2.1 Enabler of collaboration productivity (Schuh et al. 2014a)
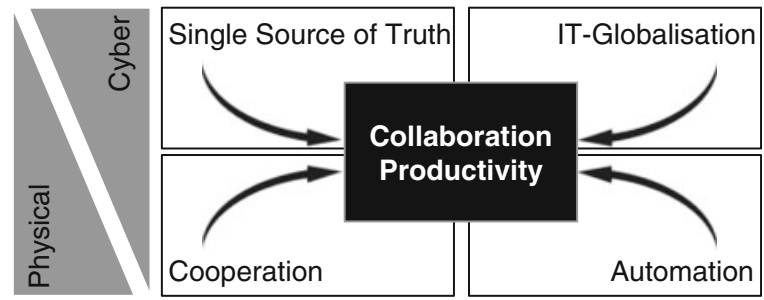

Software

Hardware

These measures can be categorised by different preconditions which are to be created within a production system. The categorisation is conducted by aid of two dimensions. The first dimension describes whether a precondition is physical or cyber, whereas the second dimension allocates the precondition to hard- or software components (Schuh et al. 2014a). By making up a matrix of the named dimensions four main preconditions can be identified which are shown in Fig. 2.1 and represent the enablers for Industrie 4.0: IT-Globalisation, single source of truth, automation and cooperation.

In order to benefit from the fourth industrial revolution, the presented enablers for collaboration productivity and thus for Industrie 4.0 have to be focused and put into use as a technological and organisational foundation. Against the background of the dimensions for the enablers of Industrie 4.0 collaboration is seen as the interworking of human and human, machine and human and machine and production system (Schuh et al. 2013a, 2014c).

In the following the four enablers for Industrie 4.0 are described as they make up the basis for the productivity increase in an Industrie 4.0-environment as well as the mechanisms and therefore the hypotheses which represent the main focus of this paper.

(1) IT-Globalisation The intersection of cyber and hardware concentrates on the IT-Globalisation. Computers present potentials and advantages for economic growth in comparison to the investment costs (Brynjolfsson and Hitt 2000; Schuh et al. 2014a). In the near future the speed of computers will increase even more and therefore becomes less expensive just as storage capacity (Hilbert and López 2011). This will especially enhance producing companies to store massive information in a central cloud which can be accessed from all over the world due to increased speed (Schuh et al. 2014a). On top the increased speed will allow faster extensive simulations of different aspects of a company as well as the processing of huge amounts of data, which are already collected by companies, but cannot be used adequately.

(2) Single source of truth To receive viable simulations and information it is inevitable for a company to embed all product lifecycle data along the value chain within a single database (Schuh et al. 2011). Consistent information within this "single source of truth" has to be maintained in terms of product lifecycle management (PLM) to make all changes to product and production 
visible and avoid ambiguity (Gecevska et al. 2012; Eigner and Fehrenz 2011; Bose 2006; Schuh et al. 2014a). "Single source of truth" is enhanced by the enabler IT-Globalisation, as cloud storage and access is supported and improved.

(3) Automation Further enabler for Industrie 4.0 are cyber-physical systems which combine computers, sensors and actuators and therefore link up the virtual with the physical environment (Lin and Panahi 2010). This leads to automated and decentralised processes which can be combined to collaboration networks (Frazzon et al. 2013; Schuh et al. 2014a). These cyber-physical systems are able to adapt to dynamic requirements and therefore are self-optimising (Wagels and Schmitt 2012). Next to the improvement of machine collaboration this enabler empowers the embedment of skilled workers in such a machine system and enables even more flexible production processes (Schuh et al. 2014a).

(4) Cooperation The fourth and therefore last enabler for Industrie 4.0 is called cooperation and aims at the connection of all technologies and activities. Cooperation is already used in development projects, as for example a major NASA supplier named Thiokol achieved a reduction of development lead time by $50 \%$ due to efficient sharing and exchange of engineering data within a network of engineers (Lu et al. 2007). Networks help to improve cooperation by communicating targets and empowering decision maker's in decentralised systems (Kagermann et al. 2013; Schuh et al. 2014a).

The presented enabler depend on each other and also enhance one another as for example simulations using big data is only possible by adequate storage capacities and computing speed. Also automation and collaboration of machines and humans is not possible without the necessary cooperation. In conclusion Industrie 4.0 can only be achieved by developing and applying all four enablers simultaneously (Schuh et al. 2014a).

\subsection{Mechanisms and Target States Due to Increased Productivity}

The proposed enabler for an Industrie 4.0-environment help to increase the (collaboration) productivity significantly. This significant increase is represented by the four mechanisms "Revolutionary product lifecycles", "Virtual engineering of complete value chains", "Revolutionary short value chains" and "Better performing than engineered" (Schuh et al. 2014a). In the following for each one of the mechanisms hypotheses are presented which propose how the target state, represented by the mechanism, is to be achieved and how Industrie 4.0-enabler help to achieve them. 


\subsubsection{Revolutionary Product Lifecycles}

In today's business environment producing companies face the challenges of shorter lifecycles and micro segmentation of markets (Schuh 2007). Therefore it is essential for such companies to maintain and maybe even extend their development and innovation productivity (Schuh et al. 2013b). One performance indicator for a company's innovation productivity is the time to market. The faster a company is able to introduce new products to the market the shorter the development process has to be. This compression of the development process is made possible within an

Industrie 4.0-environment (Schuh et al. 2014a). By aid of integrated technologies and rapid prototyping companies are able to produce testable prototypes which supply viable information of the products potentials as customer feedback can be implemented immediately. Due to the new technologies the costs of an iteration and the resulting changes are not as cost intensive as before and therefore lead to a new development process in terms of time and profit which is shown in Fig. 2.2 (Rink and Swan 1979).

The adjustment of the product development process in terms of profit and time can be achieved by adapting the following hypotheses:

(1) "Trust based and iterative processes are more productive and more efficient than deterministically planned processes"

Trust based and iterative processes lead to an increase in productivity as developers are afforded time and space to invent, albeit within set boundaries, and therefore generate more innovations than within a deterministically planned process (Paasivaara et al. 2008; Schuh et al. 2014a). As the new development process is based on a SCRUM-like approach, deterministic planning becomes less important as iterations are permitted and also promoted (Schwaber and Beedle 2002; Schuh et al. 2014a). Thus planning a whole development process would take up a huge amount of time considering all possible solutions within the design space. Unlike nowadays the iterations and adaptations due to field tests are not as cost intensive as new technologies such as selective laser melting and rapid prototyping offer "complexity for free" and are able to generate new prototypes in significant less time and with less recourses.

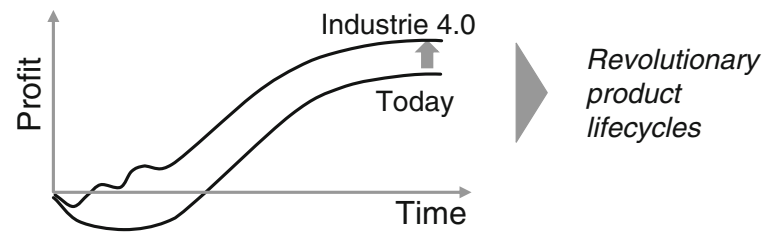

Fig. 2.2 Revolutionary product lifecycles (Schuh et al. 2014a) 
(2) "The speed of a planning process is more important than the quality of the planning process itself'

The second hypothesis mainly aims at the planning process within product development projects. Nowadays projects are accurately planned, which takes up a great amount of time and also causes analogous costs within a state where a lot of uncertainty is common due to unknown risks within the development process. Therefore the current process is also based on the assumption that adaptations and alteration to the project are to be prevented (Brettel et al. 2014b). However, the development process within the Industrie 4.0-environment supports iterations and therefore alterations. Thus it is more important to quickly generate a plan in order to start the next development step than to accurately predict the outcome of this development step (Gilbreth 1909; Mees 2013). Furthermore the new integrated production technologies allow adaptations which might be necessary due to unforeseen events.

\subsubsection{Virtual Engineering of Complete Value Chains}

Software tools such as OptiWo are able to virtualise global production networks and help to optimise the production setup (Schuh et al. 2013c). By aid of such tools companies now have the opportunity to simulate their whole production network. This virtualisation and simulation can reveal possible capacity problems as well as problems within the general workflow (Schuh et al. 2014a). By simulating the value chain in a short amount of time one is able to counteract possible problems before they arise, which enhances the decision capability. Furthermore the virtualisation of the value chain supports product development, as the effects of measures taken in the early stages of a product's lifecycle can be simulated and evaluated. The prediction of possible problems due to faults within product development contains a high cost potential as the error correction costs increase exponentially over time (Pfeifer 2013). Therefore the virtualisation enhances the iterative development and consequently also the radically short development processes as virtual try-out is supported (Takahashi 2011). To get a valuable decision capability based on simulations it is necessary to execute an adequate number of simulations (Fig. 2.3).

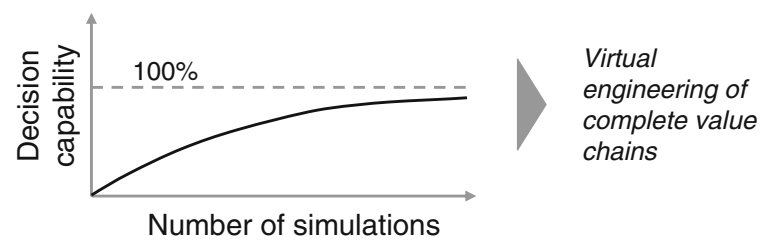

Fig. 2.3 Virtual engineering of complete value chains (Schuh et al. 2014a) 
(1) "The quality of planning decisions is enhanced by a fast development of the complete virtual value chain"

In order to get an even better decision making capability it is very important to gain information as fast and early as possible. Even in an Industrie 4.0-environment with high speed computers simulation takes time and different situations have to be generated. Furthermore the rule of ten states that costs for error correction increase exponentially (Pfeifer 1996). Therefore the fast implementation of a virtual value chain helps to start simulating as early as possible in order to detect possible errors which in a next step can be addressed by adequate measures. This results into better planning decisions and results due to preventive measures.

(2) "Increasing the number of different simulation scenarios improves decision making due to better understanding and examination of assumptions"

Following the law of large numbers in which the accuracy of the relative probability is increased by an infinite number of attempts, the amount of simulations for a specific situation within the value chain effects the capability to make right decisions. The logical implication being, that with an increasing number of simulation scenarios the actual outcome of a given set up of for example a manufacturing process and its ambient conditions will be detected and therefore the right measures can be taken. In analogy to the law of great numbers of Bernoulli where increasing the number of experiments leads to a higher accuracy (Albers and Yanik 2007; Schuh et al. 2014a) this hypothesis states, that the possibility of simulating the future case increases adequately and therefore the outcome of the future scenario is known due to the simulation and therefore can be taken into account for the decision. In combination with the Industrie 4.0-enabler "Speed" the basis of a decision can be improved even more as a computer is able to rapidly combine the results of the simulation.

\subsubsection{Revolutionary Short Value Chains}

As described before, companies have to offer more and more individualised products in order to meet the customer requirements. As an example of the automobile industry the Ford Fusion is offered in over 15 billion different configurations (Schleich et al. 2007). This trend complicates the division of labour introduced by Taylorism in terms of production and assembly lines, as machines in general are only able to fullfil one specific task. Therefore the complexity of the whole production system is increased. In order to allow even more individualised products the integration of production steps and thus the integration of functions within production systems is inevitable. This leads to a reversion of Taylorism implemented during the second industrial revolution. Instead of the division of labour by means of a conveyor belt production cells are to be established, allowing an employee to 


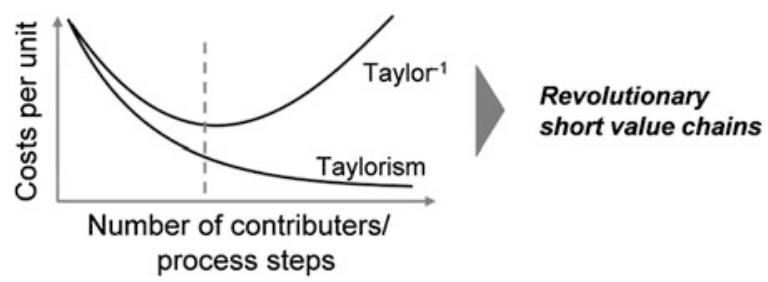

Fig. 2.4 Revolutionary short value chains (Schuh et al. 2014a)

take over autonomous responsibility and give this specific employee decision capability (Schuh et al. 2014a).

Within a production process for highly customised products there is an optimal number of contributors or process steps in one production cell which have to collaborate in order to achieve minimal costs for the produced product (Fig. 2.4).

(1) "Shortening the process chain by aid of integrated technologies increases productivity"

Especially within machinery and plant engineering products are produced within a job shop production process. The results of several analyses of the Laboratory for Machine Tools and Production Engineering (WZL), especially in companies with individual and small series production, demonstrated that by passing on the product to the next manufacturing and production step a lot of time elapses due to set up time and downtimes of the machines. As the process chain becomes longer the respective setup and downtimes become longer as well. Long process chains are often caused by the inability to process a unit within one production cell. By integrating different technologies into one machine within an Industrie 4.0-environment the possibility arises to process one specific product within a single or at least a few production cells. Thereby the value chain could be shortened in order to reach a minimum costs per unit by eliminating set up and machine downtime.

(2) "Continuous process responsibility increases the productivity of the processes"

As stated before, many companies face the challenge of more and more individualised products. Within Industrie 4.0 it is conceivable that customisation will be taken even further (Brecher et al. 2010; acatech 2011) and companies will not only have to produce customised products of the same kind such as cars, but will have to manufacture totally different products. In this case it is hardly possible to divide the production and manufacturing process into smaller parts in terms of Taylorism. In order to still be able to increase productivity one option is the continuous responsibility of one employee for the whole value creation process of one specific unit of a product. This approach has advantages especially if enhanced by Industrie 4.0. First of all in combination with integrated technologies and processes the continuous responsibility will lower inefficiencies in terms of set up times on the side of the employee as handovers are reduced and the new employee doesn't have to 
adapt to the specialties of the customised product. As mistakes mostly occur during handovers a continuous responsibility also prevents these mistakes (Prefi 2003). Secondly the responsibility for a whole value creation process gives the employee pride in the product he produces as he sees the development of the product. It was shown, that it is important for an employee to see the results of his work, that the results were impacted by his skills, that they solved difficult problems and that they felt they were trusted (Nakazawa 1993). It is easy to imagine, that the above mentioned feelings are hard to achieve, if the production process is divided into many small steps due to Taylorism. Therefore a continuous process responsibility can help to increase motivation and therefore productivity. This kind of attachment and motivation to increase productivity is already used within the engine manufacturing process at Mercedes-AMG where one single engine is handcrafted and even signed by one single engineer (Höltkemeier and Zwettler 2014).

\subsubsection{Better Performing Than Engineered}

The mechanism of "Better performing than engineered" aims at the self-optimising capabilities of production systems which are already theoretically possible (Schuh et al. 2013d). With the ongoing advancement of self-optimising production systems machines should be able to reach a productivity level which exceeds the previously determined maximum due to cybernetic effects (Schuh et al. 2014a). These effects would involve structural changes to a system as a response to varying conditions appealing to the production system. An example for such a self optimisation would be a productivity of 15,000 units whereas the estimated maximum before self optimisation was 10,000 units. This kind of self optimisation would have a huge impact on the flexibility and reactivity of a production system and therefore contribute significantly to its productivity. The described self-optimising effect is shown in Fig. 2.5.

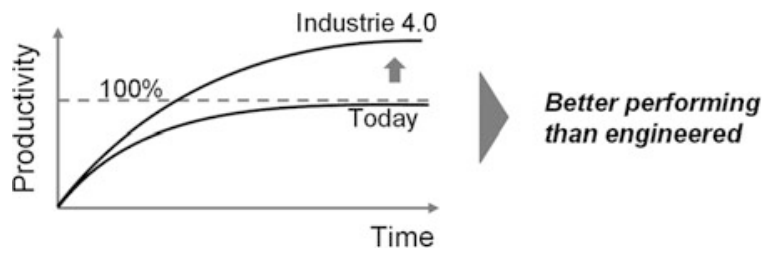

Fig. 2.5 Better performing than engineered (Schuh et al. 2014a) 
(1) "When a self-optimising system reaches its process performance limits the self-optimisation constitutes a process pattern change"

In general systems of all kinds are optimised within the systems current state in order to reach an optimal performance level. Usually this level is approached by a decreasing speed. Whenever the optimal performance level is reached no further optimisation is possible. The only way to improve performance beyond this theoretical border is a change within the system itself or within the process pattern. An example for this kind of optimisation is represented by the Fossbury Flop whereas the jumping height could not be improved by the old jumping technique the Fossbury Flop enabled athletes to reach new records. For a production system this pattern change describes the dynamic adaption of the target system. The production system does not only try to reach an exogenous given target but adjusts this target based on internal decisions (Schmitt and Beaujean 2007). Within Industrie 4.0 self-optimising systems therefore should be able to acknowledge performance boarders and change process patterns in order to surpass them.

(2) "Self-optimisation requires an over determined sensor actuator system"

The term "determined" states the described system is fixed within its pre determined patterns, as no degrees of freedom are available to the system to adapt its patterns. For an over-determined system however, there is a possibility to change patterns. For example within a pattern change one degree of freedom can be taken away in exchange for another degree of freedom. Thus a system can adapt to changing requirements. This type of learning and adaption requires a cognitive system, which contains sensors and actuators (Zaeh et al. 2010). Nowadays the change within patterns is usually supported by a human worker (Schmitt et al. 2007), who then expands the sensor actuator system of the production system. To replace the human intervention it is therefore necessary to provide the self-optimising systems with an over-determined sensor actuator system.

\subsection{Conclusion}

This paper pursues the vision that one core characteristic of Industrie 4.0 is a raise in collaboration productivity. Accordingly, four main enablers as preconditions for Industrie 4.0 and collaboration are introduced. These enablers can help to reach mechanisms or target states, which represent a significant increase in productivity. The paper introduces and explains two hypotheses for each of the four mechanisms, which indicate how the Industrie 4.0-mechanisms can be reached and how the Industrie 4.0-enablers help implementing the mechanisms. Future research will focus on the empirical validation of the depicted hypotheses and mechanisms in order to strengthen or adapt the pursued vision. 
Open Access This chapter is distributed under the terms of the Creative Commons Attribution Noncommercial License, which permits any noncommercial use, distribution, and reproduction in any medium, provided the original author(s) and source are credited.

Acknowledgments The authors would like to thank the German Research Foundation DFG for the kind support within the Cluster of Excellence "Integrative Production Technology for HighWage Countries". The authors would further like to thank Anja Ruth Weber and Jan-Philipp Prote for their collaboration in the project.

\section{References}

acatech (2011) Cyber-Physical Systems, Driving force for innovation in mobility, health, energy and production (acatech Position paper).

Albers R, Yanik M (2007) Binomialverteilung, In Skript zur Vorlesung „Stochastik“, Universität Bremen, http://www.math.uni-bremen.de/didaktik/ma/ralbers/Veranstaltungen/Stochastik12/.

Bose R (2006) Understanding management data systems for enterprise performance management, In Industrial Management \& Data Systems 106 (1), pp. 43-59.

Brecher C, Jeschke J, Schuh G, Aghassi S, Arnoscht J, Bauhoff F, Fuchs S, Jooß C, Karmann W. O, Kozielski S, Orilski S, Richert A, Roderburg A, Schiffer M, Schubert J, Stiller S, Tönissen S, Welter F (2010) Individualised Production, In Integrative Production Technology for HighWage Countries, Berlin: Springer, pp. 77-239.

Brettel M et al. (2014b) Increasing the Problem Solving Speed Through Effectual Decision Making, In AOM 2014: The 74th Annual Meeting of the Academy of Management - August 1-5, 2014, Philadelphia, PA.

Brettel M, Friederichsen N, Keller M, Rosenberg M (2014a) How Virtualization, Decentralization and Network Building Change the Manufacturing Landscape: An Industry 4.0 Perspective, In International Journal of Mechanical, Industrial Science and Engineering 8 (1), pp. 37-44.

Brynjolfsson E, Hitt L M (2000) Beyond Computation: Information Technology, Organizational Transformation and Business Performance, In The Journal of Economic Perspectives 14 (4), pp. 23-48.

Eigner M, Fehrenz A (2011) Managing the Product Configuration throughout the Lifecycle, In 8th International Conference on Product Lifecycle Management, Seoul, pp. 396-405.

Frazzon E, Hartmann J, Makuschewitz T, Scholz-Reite B (2013) Towards Socio-Cyber-Physical Systems in Production Networks, In 46th CIRP Conference on Manufacturing Systems 2013 7 (0), pp. 49-54.

Gecevska V, Veza I, Cus F, Anisic Z, Stefanic N (2012) Lean PLM - Information Technology Strategy for Innovative and Sustainable Business Environment, In International Journal of Industrial Engineering and Management 3 (1), pp. 15-23.

Gilbreth F (1909) The bricklaying System, The MC Clark publishing co, New York.

Hilbert M, López P (2011) The World's Technologica Capacity to Store, Communicate, and Compute Information, In Science 1 April 2011 (332), pp. 60-65.

Höltkemeier U, Zwettler M (21.02.2014) High-Speed-Junkie für einen Tag, In Konstruktionspraxis February 2nd 2014, http://www.konstruktionspraxis.vogel.de/themen/antriebstechnik/motoren/ articles/435236/index2.html (accessed on 10 September 2014).

Imtiaz J, Jasperneite J (2013) Scalability of OPC-UA Down to the Chip Level Enables "Internet of Things", In 11th IEEE International Conference on Industrial Informatics, Bochum, pp. 500-505.

Kagermann H, Wahlster W, Helbig J (2013) Recommendations for implementing the strategic initiative Industrie 4.0, Acatech, pp. 13-78. 
Lin K-J, Panahi M (2010) A Real-Time Service-Oriented Framework to Support Sustainable Cyber-Physical-Systems, In IEEE 8th International Conference on Industrial Informatics 2010, Osaka, pp. 15-21.

Lu S C-Y, ElMaraghy W, Schuh G, Wilhelm R (2007) A Scientific Foundation of Collaborative Enginereering, In CIRP Annals - Manufacturing Technology 56 (2), pp. 605-634.

Mees B (2013) Mind, Method and Motion, In The Oxford handbook of management theorists, pp. 32-48.

Nakazawa H (1993) Alternative Human Role in Manufacturing, In AI \& SoC (1993) 7, pp. $151-156$.

Paasivaara M, Durasiewicz S, Lassenius C (2008) Distributed Agile Development: Using Scrum in a Large Project, In 2008 IEEE International Conference on Global Software Engineering, Bangalore, pp. 87-95.

Pfeifer T (1996) Qualitätsmanagement - Strategien, Methoden, Techniken, München: Hanser.

Prefi T (2003) Qualitätsorientierte Unternehmensführung, P3 - Ingenieurges. für Management und Organisation.

Rink D R, Swan J E (1979) Product life cycle research: A literature review, In Journal of Business Research 7 (3), pp. 219-242.

Russwurm S (2013) Software: Die Zukunft der Industrie, In Industrie 4.0 - Beherrschung der industriellen Komplexität mit SysLM, pp. 21-36.

Schleich H, Schaffer J, Scavarda L F (2007) Managing Complexity in Automotive Production, In 19th International Conference on Production Research 2007, Valparaiso, Chile.

Schmitt R et al (2007) Self-optimising Production Systems, In Integrative Production Technology for High-Wage Countries, Berlin: Springer, pp. 697-971.

Schmitt R, Beaujean P (2007) Selbstoptimierende Produktionssysteme - Eine neue Dimension von Flexibilität, Transparenz und Qualität, In ZWF Jahrg. 102 (2007), pp. 520-524.

Schuh G (2007) Excellence in production, Apprimus Wissenschaftsverlag, Aachen.

Schuh G, Dölle C, Riesener M, Rudolf S (2014b) Lean Innovation durch globales Komplexitätsmanagement, In Industrie 4.0: Aachen Perspektiven, Aachener Werkzeugmaschinenkolloquium 2014, pp. 145-170.

Schuh G, Potente T, Fuchs S, Thomas C, Schmitz S, Hausberg C, Hauptvogel A, Brambring F (2013d) Self-Optimising Decision-Making in Production Control, In Robust Manufacturing Control, Berlin: Springer, pp. 443-454.

Schuh G, Potente T, Kupke D, Varandani R (2013c) Innovative Approaches for Global Production Networks, In Robust Manufacturing Control, Berlin: Springer, pp. 385-397.

Schuh G, Potente T, Varandani R, Hausberg C, Fränken B (2014c) Collaboration Moves Productivity To The Next Level, To be published in 47th CIRP Conference on Manufacturing Systems 2014.

Schuh G, Rudolf S, Arnoscht J (2013b) Product-Oriented Modular Platform Design, In Coma '13 International Conference on Competitive Manufacturing Proceedings.

Schuh G, Stich V, Brosze T, Fuchs S, Pulz C, Quick J, Schürmeyer M, Bauhoff F (2011) High resolution supply chain management: optimized processes based on self-optimizing control loops and real time data, In Prod. Eng. Res. Devel. 5 (4), pp. 433-442.

Schuh G, Potente T, Wesch-Potente C, Hauptvogel A (2013a) Sustainable increase of overhead productivity due to cyber-physical-systems, In Proceedings of the 11th Global Conference on Sutainable Manufacturing - Innovation Solutions, pp. 332-335.

Schuh G, Potente T, Wesch-Potente C, Weber A R, Prote J-P (2014a) Collaboration Mechanisms to increase Productivity in the Context of Industrie 4.0, In 2nd CIRP Robust Manufacturing Conference (RoMac 2014), pp. 51-56.

Schwaber K, Beedle M (2002) Agile Software Development with Scrum, Pearson Studium, Upper Saddle River, NJ.

Takahashi S (2011) Virtual Tryout Technologies for Preparing Automotive Manufacturing, In Transactions of JWRI 2012, Osaka. 
Wagels C, Schmitt R (2012) Benchmarking of Methods and Instruments for Self-Optimization in Future Production Systems, In 45th CIRP Conference on Manufacturing Systems 2012, pp. 161-166.

Wahlster W (2013) Industry 4.0: The Role of Semantic Product Memories in Cyber-Physical Production Systems, In SemProM: Foundations of Semantic Product Memories for the Internet of Things, Springer, pp. 15-19.

Zaeh M F, Reinhart G, Ostgathe M, Geiger F, Lau C (2010) A holistic approach for the cognitive control of production systems, In Advanced Engineering Informatics 24 (2010), pp. 300-307. 